\title{
Corporate Knows Best (Maybe): The Impact of Global versus Local IT Capabilities on Business Unit Agility
}

\author{
Magno Queiroz \\ Utah State University \\ magno.queiroz@usu.edu
}

\author{
Paul Tallon \\ Loyola University Maryland \\ pptallon@1oyola.edu
}

\author{
Tim Coltman \\ University of Waikato \\ tcoltman@waikato.ac.nz
}

\author{
Rajeev Sharma \\ University of Waikato \\ rsharma@waikato.ac.nz
}

\begin{abstract}
The relationship between the corporate unit and its strategic business units (SBUs) has been variously described in the IS literature as either antagonistic or affable. At a time when corporate units are considering how to share platform-based capabilities (dubbed global IT) with SBUs, some SBUs may feel a loss of control while others see it as a chance to focus local IT on solving problems that are best handled by SBUs. Using data from an international survey of CIOs in the U.S., Germany, and Australia, we find that platform or global IT capabilities are associated with higher SBU agility notably when SBUs operate in a relatively stable environment. We also find that local IT influences $S B U$ agility, particularly if $S B U$ s have high levels of IT autonomy. Thus, the search for SBU agility may prompt corporate units to balance use of local and global IT resources and capabilities.
\end{abstract}

\section{Introduction}

Multi-business organizations (MBOs) segmented by market, product type or location are the most pervasive type of organization structure in use today. Companies such as Stanley, Black \& Decker, General Motors, and Dell EMC employ a corporate entity that oversees a plethora of SBUs. While the corporate unit provides high-level guidance on strategic issues, local SBUs may retain some degree of autonomy over customer service, supply chain, pricing, and information technology (IT) decisions in their specified end markets. More recently, with an eye toward greater economies of scale and scope, corporate units are endeavoring to consolidate support for shared SBU processes (IT, legal, HR, and finance) at the corporate level [22].

Corporate-led IT services are of particular interest as some SBUs may feel that any corporate mandate to use shared IT - while good for the firm as a whole represents a loss of autonomy. The belief that local or
SBU-based IT needs are so idiosyncratic as to cast doubt on the wisdom of using shared IT resources - a one size fits some rather than a one size fits all SBUs has led SBU managers to fear a loss of agility and an associated decline in SBU performance. Yet, one could also argue that shared IT support could give SBUs an opportunity to focus local IT - over which they retain control - on local activities that are particular to each SBU [22]. This could mean increased use of local IT for agility because of SBUs' focus on idiosyncratic local activities needed to exploit any knowledge they possess of their particular markets.

Past studies show that IT is a critical predictor of agility, defined as the ability to detect and respond to opportunities and threats with ease, speed, and dexterity $[15,21]$. One question that remains unresolved in the IS literature is whose IT - SBU IT or corporate IT - is a better predictor of SBU agility? This is an important issue to consider in light of the growing trend toward corporate IT platforms and the effects on corporate and local IT support $[13,14] .{ }^{1}$ We offer answers to this question in this paper using data from an international survey of CIOs in Australia, the U.S., and Germany. Our results highlight the positive and significant effects of SBU use of corporate IT platforms on SBU agility. This relationship is especially evident in more stable environments, less so in unstable environments where the uncertain nature of each SBU's market and the knowledge possessed by them call for local rather than global IT to drive SBU agility. We also find that when SBUs have a high degree of IT autonomy, SBU agility is driven less by corporate IT and more by high levels of digitized SBU processes. When SBUs enjoy less IT autonomy - that is when they are obliged to rely on the corporate unit greater SBU process digitization has little or no effect on SBU agility. In the next section, we outline our theory and hypotheses where we explore the nature of global and local IT support for SBU agility.

\footnotetext{
1 Corporate IT platforms refer to technology assets and services - hardware, applications, data, networks, and management services - that are shared across SBUs [12].
} 


\section{Theoretical Development}

Existing studies show that agility drives corporate financial performance and strategic positioning $[2,15]$. SBUs are increasingly seen as the front line of MBOs in the sense that, as market or customer-facing units, they are the first to see new threats and opportunities in key markets and the first to sense the emergence of general economic downturns.

Prior studies note that the relationship between corporate units and their family of SBUs is often complex and can, on occasion, present barriers to SBU agility [9, 11]. While Kownatzki et al. [9] find that corporate unit intervention in SBU affairs can help in the articulation of clear financial and strategic goals, such interventions can directly limit SBU autonomy and flexibility. Equally, Tanriverdi [22] indicates that imposing shared IT resources or capabilities on SBUs while aiming to centralize the management of those resources or capabilities can further the corporate unit's overall goals but it can equally hinder SBUs' autonomy and flexibility. As such, the benefits that MBOs generate from shared IT resources and capabilities depend on whether they can balance the competing goals of the corporate unit with those of their SBUs [22].

The purpose of SBUs is to create and apply local knowledge within unique local market segments [7]. The ability to react to sudden market change matters to SBUs as they face ever-shrinking product life cycles, disruptive competitors, shifting customer tastes or new pricing structures $[7,11]$. Oftentimes, a desire to stay ahead of change has led the corporate unit to inject itself into local SBU decision-making. This can involve the provisioning of corporate-led IT platforms that try to automate or support common processes across many SBUs [12]. The challenge with doing this is to strike a balance between using standardized IT that meets the needs of most SBUs versus others whose needs require more tailored IT solutions. Research on IT architecture indicates that corporate IT platforms can - through shared IT capabilities - streamline IT spending by curtailing unnecessary IT while allowing knowledge of shared IT applications to flow between SBUs [14]. This same body of literature also notes that even as IT platforms allow greater global flexibility across the company, the drive to deliver an "optimized core" - a one size fits all SBUs approach to meeting IT needs - can greatly obstruct local flexibility $[13,14]$. At some point, firms may seek to modularize their corporate IT platforms - thereby returning some degree of flexibility and autonomy to SBUs - but only $6 \%$ of firms have achieved this [14]. Most firms appear to have a type of siloed structure in which SBUs retain control over local IT. The question, therefore, remains as to how different IT owners - corporate (global IT) or SBU (local IT) - contribute to SBU agility.

Underlying the question of whose IT - corporate or SBU - matters to SBU agility is the very real possibility of tension in the relationship between the corporate unit and its SBUs. It is natural to expect SBUs to want total autonomy over all aspects of their business but we also know that optimizing performance for the company as a whole may require limiting that autonomy. As we know from agency theory, information asymmetry (the fact that SBUs know more about their specific markets than the corporate unit) and the associated costs of sharing key information with the corporate unit may make some form of SBU autonomy inevitable. That fact may

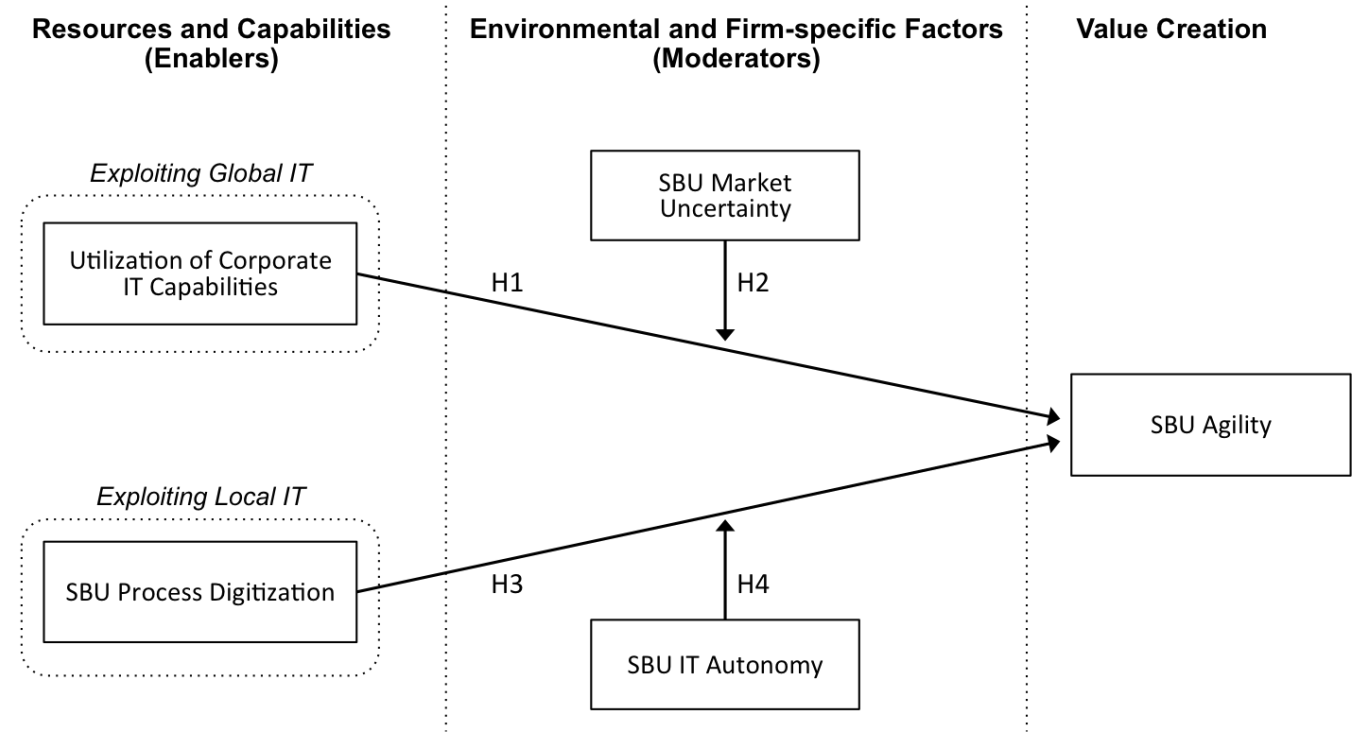

Figure 1. Conceptual model 
lessen the blow of having the corporate unit control all aspects of SBU decision making but taking any decision rights from the SBU will likely create tension. Beyond tension which might be considered by some as a structural issue is the question of what is best for firm performance. If the corporate unit limits SBU autonomy to an excessive degree, SBU agility could suffer. If that were to happen, the fortunes of the firm could suffer and so the question of whose IT matters to $S B U$ agility is of critical import.

To answer this question, we first create a research model to assess the conditions under which corporate IT and local IT shape SBU agility. The logic underlying our conceptual model reflects earlier work on resource-based theory that posits that 1) organizational resources and capabilities create value for firms and, 2) the extent of value created is impacted by external and internal (or firm-specific) factors such as market uncertainty and IT autonomy [17]. In our model outlined in Figure 1, we propose four hypotheses to capture the effects of global (corporate IT platform) and local IT (SBU IT) on SBU agility. Our model contains two main effects and two moderation effects. We next review our hypotheses.

\subsection{The Role of Corporate IT Platforms}

In recent years, firms have gone to great expense to develop far-reaching corporate IT platforms. ERP systems are one way that firms have tried to standardize on a set of shared IT resources and capabilities that can be used across the entire business. For example, the Danish food ingredients conglomerate, Danisco, created its corporate IT platform around the SAP ERP R/3 system as a way to both modularize and standardize its IT resources and capabilities for use across its family of SBUs [24].

The modular nature of ERP permits additional IT capabilities to be added to the core as a way to satisfy individual SBUs. These capabilities may be critical for some SBUs but optional for others who have, at present, limited need for their deployment. Fichman [4] and Sambamurthy et al. [15] note that real / digital IT options - which IT platforms often represent - are a useful corporate asset which, if exercised, can have implications for SBU agility. An SBU looking for data analytics capabilities can, for example, avoid the cost and time needed to create local capabilities and instead leverage data analytics capabilities within the corporate IT platform. This was the approach used by Caesars Entertainment (Harrah's) to create their firm-wide data analytics capabilities [16]. Besides leveraging shared IT capabilities, SBUs can also look to IT platforms to scale up IT support for SBU processes since IT platforms often sit astride highly scalable cloud technologies. As such, SBU agility is likely to be tied to SBUs' ability to leverage global IT capabilities as provided by a corporate-wide IT platform. This leads to the following hypothesis:

\section{H1: SBU utilization of corporate IT capabilities has a positive effect on $S B U$ agility.}

SBUs in the same firm can face different degrees of market uncertainty given their focus on different types of product, customer or geography. To the extent that SBUs operate in unpredictable or volatile markets, it may be more limiting to rely on a corporate IT platform to support all of their IT needs. Their ability to operate in uncertain markets can be impeded if IT capabilities needed to respond to changes in a specific market are not present in the corporate IT platform. Hence, a one size fits all IT support model could be a limitation in a market where a customized form of IT support is desired. However, if SBUs are in predictable markets, there is less risk associated with using an IT platform to support their needs. As such, market uncertainty is a potential moderator of the link between an SBU's utilization of the corporate IT platform and SBU agility. Therefore, we hypothesize:

\section{H2: The effect of SBU utilization of corporate IT capabilities on $S B U$ agility is moderated by SBU market uncertainty.}

\subsection{The Role of Local IT: Process Digitization}

IT support for key SBU activities must come from somewhere. If a corporate IT platform does not exist or fails to provide whatever level of IT support is needed by the SBU, the SBU may have no option but to turn to local IT to meet its immediate needs. Since SBU agility is tied to an ability to create and process data or insights about localized market threats or opportunities, local IT does not have to focus on sanitizing or aggregating data for transmission to corporate decision makers. Instead, each SBU is free to develop IT applications and support mechanisms that best meet its needs without having to directly limit its IT options to whatever is acceptable to the corporate unit or to its fellow SBUs.

The effect of IT on organizational agility has been well documented in the literature [2, 21]. An extension of these findings says that local IT - as controlled by the SBU - is equally likely to have a positive impact on SBU agility. A related argument says that process digitization - meaning the extent to which IT is used to support key business processes at the SBU level - is likely to play a role in improving agility within individual processes. When seen at the process rather 
than firm-level, process digitization can create spillover effects whereby the effects of process digitization in one area of the value chain can spillover to downstream processes within the value chain [20]. For example, process digitization in the supply chain can, by making it easier to monitor inventory levels, help to improve manufacturing throughput. If process digitization is ineffective - particularly in an area that is at the heart of the business strategy - it may have a negative effect on downstream processes within the value chain $[15,21]$. Using our earlier example, a lack of process digitization in the supply chain could seriously limit manufacturing throughput and overall agility. Thus, increased reliance on local IT in the form of SBU process digitization can have a positive effect on SBU agility. Consequently:

\section{H3: SBU process digitization has a positive effect on $S B U$ agility.}

Decisions concerning local IT do not unfold in a vacuum, however. Divisional CIOs may be required to check in with the corporate unit to ensure that they are adhering to company policies. IT expenditure cuts could also be imposed by the corporate unit if overall company-wide performance is weak [22]. SBU IT autonomy - meaning the degree to which an SBU is able to meet its IT needs from local sources - can be the result of a negotiated process with the corporate unit as Textron - a U.S.-based military contractor - did with its five operating divisions or it could be due to failure of the corporate IT platform. Low levels of IT autonomy - where SBUs are forced to rely on the corporate IT platform to support their business needs leave less opportunity for local IT to directly shape SBU agility. Alternatively, high levels of IT autonomy free SBUs to create their own IT agenda with less corporate involvement. They can change the pace of IT deployment and reconfigure applications if needed to keep up with market change. This means that local IT can have a proportionately greater role in shaping SBU agility. There is, as such, a degree of substitution between global and local IT. When SBUs have a choice as to how they will meet their IT needs whether from local or global sources - they may be able to take advantage of certain IT capabilities offered from the corporate IT platform without having to limit local IT that might be better suited to meet the idiosyncratic needs of their local markets. Therefore, we hypothesize the following moderation hypothesis to capture this effect:

\section{H4: The effect of $S B U$ process digitization on $S B U$ agility is moderated by SBU IT autonomy.}

Taken as a whole, these hypotheses point to the potential limits of SBU IT autonomy and to when it may be best to revert to corporate control of IT in the form of a corporate IT platform through which SBU IT needs are met. Thus - as our title implies - the corporate unit may know best sometimes.

\section{Research Method}

\subsection{Data Collection}

We test our hypotheses using data drawn from an international survey of senior IT executives in 120 MBOs. Our sampling frame of 1,200 MBOs includes 800 randomly selected from the U.S. with an additional 400 from Australia and Germany. We collected data on a key market-facing SBU (usually a large SBU by revenues) in each $\mathrm{MBO}$. We define market-facing SBU as an organizational unit that satisfies the following three criteria: (1) it resides at the first level of the organizational hierarchy, i.e., immediately below the corporate headquarters; (2) it produces and delivers a distinct set of products or services to a specified external market; and (3) it has profit/loss accountability and distinct operating rules. The median SBU in our sample accounts for $40 \%$ of consolidated revenues.

We identified a Chief Information Officer (CIO) familiar with the key market-facing SBU as our key informant. It is widely acknowledged that CIOs are appropriate informants for assessing the organizational impacts of IT. As Kearns and Sabherwal [8] argue, CIOs are experienced and knowledgeable and, by virtue of their position, are aware of the views of top business executives, peers, and subordinates. To increase confidence in the appropriateness of these key informants, we also undertook a series of interviews with senior IT executives at three MBOs in the U.S. and Australia. Our interviews confirmed our informant choice by showing that CIOs are sufficiently knowledgeable to answer questions about the corporate unit and key SBUs because of their participation in IT investment decisions that affect SBUs and their awareness of the business environment in which SBUs operate.

Responses were received from 141 organizations, yielding an initial response rate of $12 \%$. Twenty-one responses were excluded due to missing data and so our final response rate is $10 \%$. While low, this is on par with survey response rates noted elsewhere in the IS literature for organizations of this magnitude and where respondents are senior corporate IT executives [5]. Our assessment of common method bias and nonresponse bias (no significant differences were observed between early and late respondents) shows that these biases are unlikely to be a major concern. 
Our sample originates in the U.S. (42\%), Germany (40\%), and Australia (18\%). On average, respondents had been in their current role for eight years and had worked at the same entity for 12 years. The sectors in our sample are: financial services $(19 \%)$, electronics $(19 \%)$, manufacturing $(17 \%)$, retail $(12 \%)$, energy $(11 \%)$, and a selection of other smaller sectors $(22 \%)$.

\subsection{Survey Measures}

The survey instrument used in our study is shown in Appendix A. The survey design was refined using feedback from pilot tests with IT executive sponsors of the MIT Center for Information Systems Research. The measures for SBU agility, process digitization, and IT autonomy were adapted from prior literature. Using prior work on both corporate IT platforms [24] and market uncertainty [18], for example, we constructed items for SBU utilization of corporate IT capabilities and market uncertainty. All survey items were assessed using a five-point Likert scale.

We measure SBU agility using eight items from Tallon and Pinsonneault [21]. In addition, we collected archival data on revenues, net incomes, and profit margin for a three-year period and used that data to cross-validate our measure of agility. The results of this analysis (not reported for brevity, but available upon request) reinforced our confidence in the measure of agility. The measure of SBU process digitization assessed the extent to which SBUs use IT to support key business processes [19]. We use five reflective items from Tallon [19] to measure digitization across key processes in the value chain: supplier relations, production and operations, product and service enhancement, sales and marketing, and customer relations. Similarly, we measure SBU IT autonomy in each of these same processes as the extent to which the IT needs of the SBU are met globally from the corporate IT platform, locally by SBU IT or through a combination of local and global IT.

Corporate IT platforms allow SBUs to more easily support the needs of their users [12, 24]. To measure SBU use of corporate IT capabilities, we employ four reflective items to capture the extent to which corporate IT platform capabilities are used to meet the SBU's IT needs. The measure for SBU market uncertainty uses distinct uncertainty indicators based on prior literature. For example, Bergh and Lawless [1] examined uncertainty in terms of volatility of sales as a way to highlight variations in customer preferences. Wallace et al. [23] examined the issue of forecasting market events while Sirmon et al. [18] posit that changes in regulations are important indicators of market uncertainty. Accordingly, we assess SBU market uncertainty using formative items that assess the extent to which changes in the market environment - notably in terms of customer preferences and industry regulation - are unpredictable and difficult to accurately anticipate. Since large variations in performance and high return dispersion often signal changes in market uncertainty, we also collected archival data on return on assets (ROA), return on equity (ROE), and profit for a two-year period and examined how these financial metrics varied as a way to cross-validate our measure of uncertainty. The results of this analysis (not reported for brevity, but available upon request) increased our confidence in this measure.

Lastly, SBU agility can be affected by various internal and external factors. Control variables were used to account for differences in industry, SBU size, contribution to firm revenues, and country of origin.

\subsection{Data Analysis}

Data analysis was conducted using partial least squares, a structural equation modeling technique that uses a principal-component-based estimation technique. The software used for this analysis was SmartPLS 3.2. We first conducted an exploratory review of our survey questionnaire items as a way to test our measurement model. To evaluate our four hypotheses, we estimated the research model shown in Figure 1. We also used multigroup analysis to test our moderation hypotheses (H2, H4). Significance levels for all four hypotheses were estimated by applying the bootstrapping procedure in SmartPLS with 1,000 samples.

\section{Research Results}

\subsection{Measurement Model Assessment}

The survey items in Appendix A were first analyzed to assess construct-to-item loadings, item weights, and construct validity and reliability. The items load more highly on their intended constructs and all loadings are significant at $p<0.001$. To assess internal consistency, we next examined measures of composite reliability and cronbach's alpha. In Table 1, we summarize construct validity and reliability statistics and a correlation matrix for all constructs.

To assess discriminant validity, we compared the square root of the average variance extracted (AVE) main diagonal in Table 1 - with off-diagonal elements representing the correlation between each pair of constructs. The square root of AVE for each construct is greater than its associated off-diagonal correlations. 
Table 1. Validity and reliability statistics and correlations between constructs

\begin{tabular}{|c|c|c|c|c|c|c|c|c|c|c|c|c|}
\hline Research Constructs & CA & CR & AVE & 1 & 2 & 3 & 4 & 5 & 6 & 7 & 8 & 9 \\
\hline $\begin{array}{l}\text { 1. Utilization of } \\
\text { corporate IT capabilities }\end{array}$ & 0.83 & 0.89 & 0.66 & 0.81 & & & & & & & & \\
\hline 2. SBU agility & 0.86 & 0.89 & 0.51 & 0.53 & 0.71 & & & & & & & \\
\hline $\begin{array}{l}\text { 3. SBU process } \\
\text { digitization }\end{array}$ & 0.75 & 0.83 & 0.50 & 0.42 & 0.30 & 0.71 & & & & & & \\
\hline 4. SBU IT autonomy & 0.9 & 0.92 & 0.70 & -0.51 & -0.27 & -0.41 & 0.83 & & & & & \\
\hline $\begin{array}{l}\text { 5. SBU market } \\
\text { uncertainty }{ }^{\text {a }}\end{array}$ & n.a & n.a & n.a & -0.22 & -0.16 & -0.02 & 0.13 & n.a & & & & \\
\hline $\begin{array}{l}\text { 6. SBU contribution to } \\
\text { firm revenue } \\
{ }^{c}\end{array}$ & n.a & n.a & n.a & -0.05 & -0.02 & -0.01 & 0.02 & -0.07 & n.a & & & \\
\hline 7. SBU size ${ }^{c}$ & n.a & n.a & n.a & -0.06 & 0.04 & 0.05 & 0.08 & -0.10 & 0.27 & n.a & & \\
\hline 8. Country of origin ${ }^{c}$ & n.a & n.a & n.a & 0.05 & 0.05 & 0.02 & -0.04 & -0.17 & -0.10 & -0.08 & n.a & \\
\hline 9. Industry type ${ }^{c}$ & n.a & n.a & n.a & 0.04 & -0.03 & -0.08 & -0.15 & -0.10 & -0.03 & 0.01 & 0.19 & n.a \\
\hline \multicolumn{13}{|c|}{$\begin{array}{l}\text { Notes: } \mathrm{CA}=\text { Cronbach's Alpha; } \mathrm{CR}=\text { Composite Reliability; AVE = Average Variance Extracted; The bold } \\
\text { numbers on the diagonal are the square root of the AVE; }{ }^{a} \text { Formatively modeled construct; }{ }^{c} \text { Control variable; } \\
\text { n.a. = not applicable; Off-diagonal elements are correlations between each pair of constructs. }\end{array}$} \\
\hline
\end{tabular}

We also performed a heterotrait-monotrait (HTMT) test for discriminant validity. HTMT ratios range from 0.01 to 0.61 , below the 0.85 threshold [6].

A further risk to validity is the potential for multicollinearity. To address this issue, we performed a series of collinearity tests. In the case of reflective measures, these tests reveal minimal collinearity with all variance inflation factors (VIF) at or below 2.4 as against a suggested maximum of 10 [10]. In the case of formative measures, multicollinearity can more easily destabilize the model. If measures are too highly correlated, it may suggest that multiple indicators are tapping into the same aspect of the construct domain. Hence, with formative measures, multicollinearity poses more of a problem and the VIF statistic should not exceed 3.3 [10]. The VIFs for our three formative indicators are 1.017, 1.204, and 1.185 (below the suggested maximum of 3.3), which imply that multicollinearity is not a concern. Together these results indicate that our measures are valid and reliable.

\subsection{Hypotheses Testing}

We test our hypotheses by estimating the model shown in Figure 1. Our results appear in Figure 2.

The results for $\mathrm{H} 1$ find that SBU utilization of corporate IT capabilities has a significant positive effect on SBU agility $(\beta=0.48 ; p<0.001)$. Hence, H1 is supported. In the case of $\mathrm{H} 2$ - the first of our two moderation hypotheses - we found that SBU market uncertainty moderates the relationship between SBU use of corporate IT capabilities and SBU agility $(\beta=$ $0.25 ; p<0.01)$. Figure 3 reveals this interaction effect, showing that while the relationship between SBU use of corporate IT and SBU agility is positive when market uncertainty is either low (stable environment) or high (unstable environment), the size of the relationship is higher when uncertainty is low.

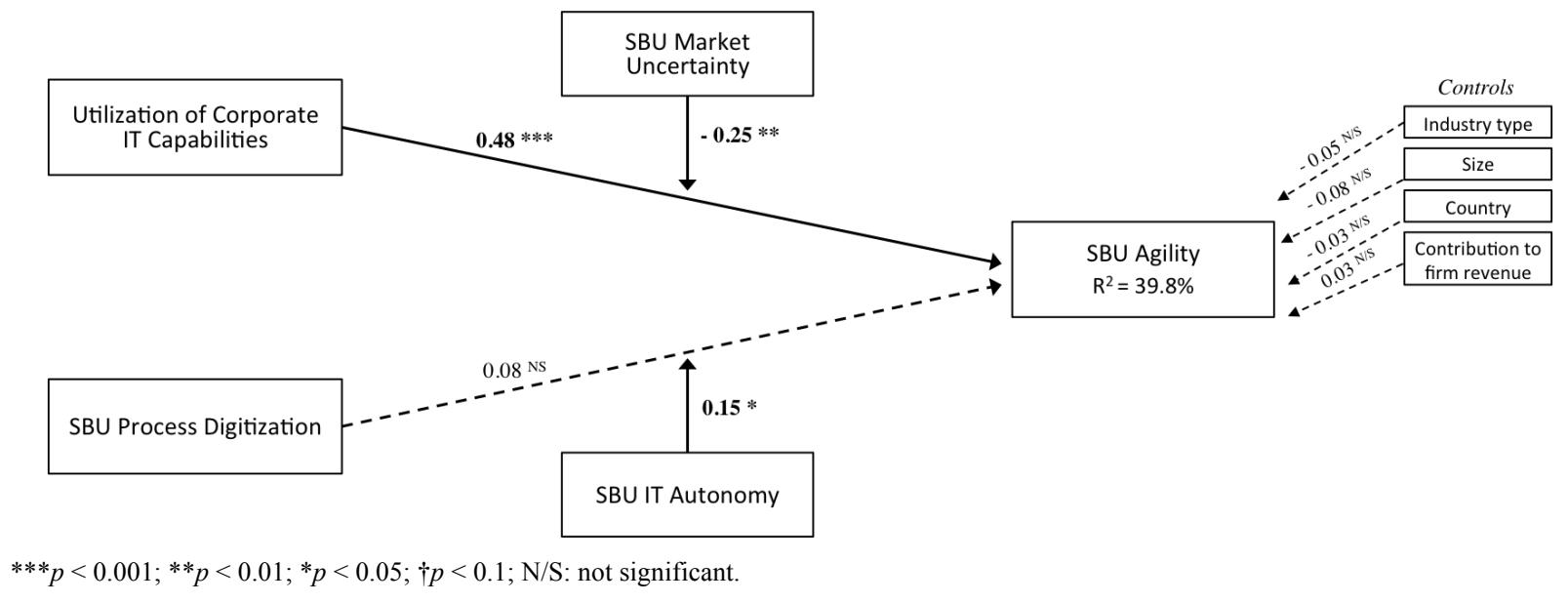

Figure 2. Results of the research model 


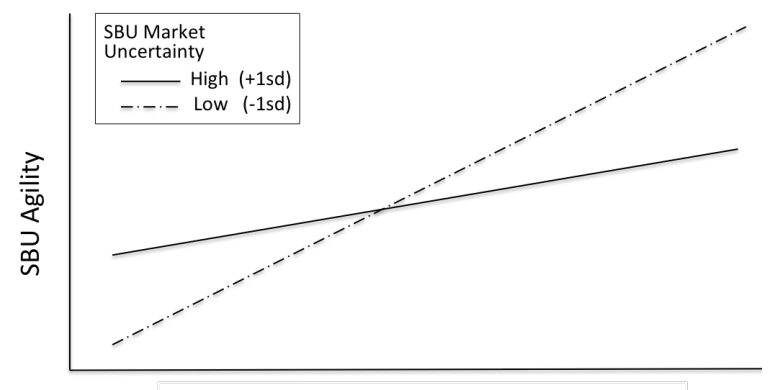

Utilization of Corporate IT Capabilities

Figure 3. The relationship between SBU utilization of corporate IT capabilities and SBU agility as a function of SBU market uncertainty

The results for $\mathrm{H} 3$ find that the effect of SBU process digitization on SBU agility is not significant $(\beta$ $=0.08 ; \mathrm{N} / \mathrm{S}$ ). Thus, we reject $\mathrm{H} 3$. However, our assessment of the moderation effects of IT autonomy confirms that this relationship varies between SBUs with low and high IT autonomy. While the relationship is not significant for SBUs whose IT decisions are primarily made by the corporate unit, it is significant and positive for those with relatively high IT autonomy $(\beta=0.35 ; p<0.05)$. Our results also indicate that the change in the effect of SBU process digitization as a function of IT autonomy is significant $(\Delta \beta=0.32 ; p<$ 0.05 ). As such, $\mathrm{H} 4$ is supported. Figure 4 highlights this interaction effect in graphical form for SBUs with low and high levels of IT autonomy. Our analysis also shows that coefficients for controls for industry type, country of origin, SBU size, and SBU contribution to consolidated revenue were not significant. In the case of SBU contribution to revenues, our analysis suggests that our findings may apply to not just the largest, most profitable or best-known SBU but rather to multiple SBUs within the same organization.

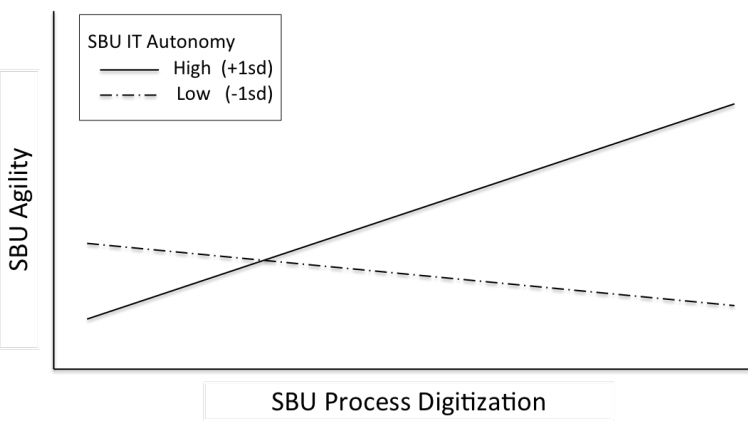

Figure 4. The relationship between SBU process digitization and SBU agility as a function of SBU IT autonomy

\subsection{Additional Analysis}

We conducted further analysis to examine the joint effects of corporate unit IT (global) and local (SBU) IT. Specifically, we examined whether SBU use of corporate IT capabilities and SBU process digitization exert joint effects on SBU agility. Our results show that their joint effects on SBU agility are not significant $(\beta=-0.13 ; \mathrm{N} / \mathrm{S})$. In addition, we examined the relationship between SBU utilization of corporate IT and SBU process digitization. We find that an SBU's utilization of corporate IT is associated with an increase in process digitization $(\beta=0.41 ; p<0.001)$. This result suggests that corporate IT plays an important role in improving IT support for SBU processes. However, as SBUs increase their use of corporate IT, they become more dependent on the corporate unit and may experience a decline in local IT autonomy. Indeed, our results show that SBU utilization of corporate IT has a negative impact on SBU IT autonomy $(\beta=-0.51 ; p<0.001)$.

\section{Discussion}

We began this study by acknowledging that while previous studies attest to the positive link between IT and agility, this relationship is more nuanced than the literature indicates since SBUs are essentially the front line of attack and defense within MBOs. With the rise of corporate IT platforms, we are driven to ask whose IT - the corporate unit or the SBU - is associated with agility. The answer - like many things in IS research depends on the organizational context. While we do not directly address the tensions that so often describe the relationship between the corporate unit and its SBUs - for example, we do not follow the money to see how IT budgets are set or whether SBU IT management have a say in how corporate IT budgets are set - this sense that the answer to the question of whose IT matters depends on the situation, helps us realize how this tension could arise. As our interaction plot shows in Figure 3, at times when market uncertainty is low, there is justification for the corporate unit to deploy (and maybe even mandate use of) an IT platform to support a wide range of SBU processes. It is easy to see, however, that not all SBUs in the same company will face equal degrees of market uncertainty and so while a corporate IT platform might work well for one SBU - such as the key SBU that we study in this paper - it may not work for all SBUs in the same firm. Beyond what we can conclude about tension between SBUs and the corporate unit, our results imply that a move to force adoption of a corporate IT platform because it fits the needs of a 
large or prominent SBU could give rise to some form of tension between SBUs.

If we consider the relationships depicted in Figure 4, some additional insights emerge. Quite simply, in cases where SBU IT autonomy is low - where the SBU's IT needs are increasingly met through the corporate unit - there is a limit on the extent to which SBU agility can be improved. This is bad news for SBUs, no matter how you look at it. No amount of process digitization is able to overcome this limitation. One must be careful to not read into this that all corporate IT platforms are bad and that efforts to create shared IT solutions and to embed those solutions in a platform is bad. There is a time and place for IT platforms but there are also limits to what they can do in practice. Corporate IT platforms and SBU IT autonomy can coexist; they are not mutually exclusive. The problem for SBUs emerges, perhaps, when SBUs have little latitude to say what they want the corporate IT platform to do for them. Giving SBUs the autonomy to decide for themselves whether and how to use the capabilities embedded in the corporate IT platform means that SBUs can have the best of both worlds. They have the ability to deploy local IT when it best suits their needs but to equally fall back on the corporate unit to support any other needs through the corporate IT platform. As highlighted in Figure 4, when SBU IT autonomy is high - that is when SBUs are allowed to retain for themselves certain IT decision rights - increases in SBU process digitation by way of local IT are consistent with increases in SBU agility. So by any measure, SBU IT autonomy is preferable. If we ponder the subject of whether the corporate unit knows best, one could argue that the answer to this is knowing when to step in and provide assistance to SBUs and, equally, when to stay out of the way.

A large body of research has considered the impacts of IT from various perspectives. SBU agility is another way to consider IT impacts. However, rather than using a historical view of how IT has impacted firm performance in the past - as has been the focus of much IS research - there is merit to looking at agility as a capability or a type of option that an SBU can trigger should the need arise. SBUs are likely the entity where the impacts of IT are first felt or, alternately, the entity that is likely to suffer most if IT is deficient or unable to respond to market changes. If so, how might we interpret our results in light of the need to combine - depending on the context - global IT in the form of a shared IT platform with local IT directly by the SBU? We explore this question by considering the implications of our findings below.

\subsection{Implications for Research}

Studies on the development and application of IT capabilities have gained a great deal of attention from academics in recent years. The question in this paper whose IT matters most to SBU agility: corporate IT or SBU IT - brings a new dimension to this stream of literature. The issue is less about IT governance or IT more generally and more about whose IT is likely to be most effective as firms seek to balance support for the unique needs of their SBUs with the potential for greater synergies across these same SBUs. Corporate unit (global) and SBU (local) IT can be substitutes in many respects for standardized processes such as HR, legal, and finance. Yet, they can also be complements if SBUs can add to the capabilities that are part of the IT platform [14]. The question that emerges from this is to ask at what point does the push by the corporate unit to embed more shared or global IT support in the corporate IT platform begin to frustrate the value that local IT brings to the SBU. As platform technologies mature, we could ask if the marginal value of local IT is likely to fall, leading the corporate unit or global IT to become a substitute for all local IT. Our results do not answer these questions directly but when we find that IT autonomy moderates the relationship between SBU process digitization and SBU agility, it leads us to ask if the scope of corporate IT platforms might grow to encompass a broader range of SBU IT support and at what point the expansion of corporate IT platforms might begin to seriously erode SBU agility.

Our results also imply that it is important to better understand how decisions are made by corporate and SBU leadership as to what the corporate IT platform will support and what residual activities must instead be supported by the SBUs. We could equally ask how these decisions are reached if SBUs are pursuing very different markets or if there is a power imbalance due to the disproportionate performance of one key SBU. These are important issues because any delays in reaching consensus about the role and use of corporate IT may be unacceptable, particularly when market conditions are unstable [3].

\subsection{Implications for Practice}

Corporate strategy looks at ways of creating value across different SBUs. The goal of the corporate unit is to optimize local or within-SBU activities and, if possible, to recognize the possibilities for synergies between SBUs. Global IT in the guise of a corporate IT platform is one way that the corporate unit can try to realize these synergies - creating value that SBUs cannot realize in isolation. Besides standard activities such as HR, legal, and finance that are likely similar across each SBU, there is growing recognition that IT can also support primary activities in the value chain 
and that the corporate unit may uncover opportunities for synergies here also. If SBUs are concerned that a move by the corporate unit to support what SBUs see as their primary value-generating activities could hurt their local business, it makes sense that the corporate unit search for ways to build consensus among SBUs. Hence, corporate units should make an effort to raise the profile of what a corporate IT platform can do for SBUs but without SBUs fearing a loss of autonomy that might impede their local success. Corporate units and SBUs can be jointly successful but success is a function of knowing when to rely on a corporate IT platform and when local IT is preferable.

Corporate IT platforms are a work in progress. If firms see corporate IT platforms as a way to reduce and eliminate a proliferation of IT standards or to better control their IT budgets, this might work but if they also curtail SBU IT autonomy, they may see a reduction in SBU agility and a commensurate fall in firm performance. This is not what firms want. It may be advisable, therefore, to retain some form of local IT autonomy within SBUs rather than to force all SBU IT managers to capitulate to corporate IT.

\section{Conclusion}

Agility is increasingly regarded as a key organizational imperative. Prior research reveals that IT plays a key role in allowing firms to be agile. However, with SBUs being on the front lines of MBOs and with a trend toward expanded use of corporate IT platforms, the question becomes: whose IT matters most to SBU agility, the corporate unit or what we call global IT because of how IT is shared or local IT as provided by SBUs? Our results show that global IT is a more important driver of SBU agility if SBUs face stable market conditions. However, when market conditions are unstable, local IT is more important. We also show that local IT has little effect on SBU agility when SBU IT autonomy is low. There is, consequently, a role for both global and local IT in boosting SBU agility. Finding the ideal tipping point between these two forms of IT support is likely to be an interesting research topic for future IS research.

\section{References}

[1] D. Bergh, and M. Lawless, "Portfolio Restructuring and Limits to Hierarchical Governance: The Effects Of Environmental Uncertainty and Diversification Strategy", Organization Science, 9 (1998), pp. 87-102.

[2] A. Chakravarty, R. Grewal, and V. Sambamurthy, "Information Technology Competencies, Organizational agility, and firm performance: Enabling and facilitating roles", Information Systems Research, 24 (2013), pp. 976997.

[3] F. Csaszar, and E. Clemons, Governance of the IT Function: Valuing Agility and Quality of Training, Cooperation and Communications, Hawaii International Conference on System Sciences, IEEE Computer Society Press, 2006.

[4] R. G. Fichman, "Real Options and IT Platform Adoption: Implications for Theory and Practice", Information Systems Research, 15 (2004), pp. 132-154.

[5] J. E. Gerow, J. B. Thatcher, and V. Grover, "Six Types of IT-Business Strategic Alignment: An Investigation of the Constructs and Their Measurement", European Journal Of Information Systems, 24 (2014), pp. 1-27.

[6] J. Henseler, C. M. Ringle, and M. Sarstedt, "A New Criterion for Assessing Discriminant Validity in Variancebased Structural Equation Modeling", Journal of the Academy of Marketing Science, 43 (2015), pp. 115-135.

[7] J. Joseph, and W. Ocasio, "Architecture, Attention, and Adaptation in the Multibusiness Firm: General Electric from 1951 to 2001", Strategic Management Journal, 33 (2012), pp. 633-660.

[8] G. S. Kearns, and R. Sabherwal, "Strategic Alignment between Business and Information Technology: A Knowledge-based View of Behaviors, Outcome, and Consequences", Journal of Management Information Systems, 23 (2007), pp. 129-162.

[9] M. Kownatzki, J. Walter, S. W. Floyd, and C. Lechner, "Corporate Control and the Speed of Strategic Business Unit Decision Making", Academy of Management Journal, 56 (2013), pp. 1295-1324.

[10] S. B. MacKenzie, P. M. Podsakoff, and N. P. Podsakoff, "Construct Measurement and Validation Procedures in MIS and Behavioral Research: Integrating New and Existing Techniques", MIS Quarterly, 35 (2011), pp. 293-334.

[11] J. A. Martin, and K. M. Eisenhardt, "Rewiring: CrossBusiness-Unit Collaborations in Multibusiness Organizations", Academy of Management Journal, 53 (2010), pp. 265-301.

[12] P. Reynolds, and P. Yetton, "Aligning Business and IT Strategies in Multi-Business Organizations", Journal of Information Technology, 30 (2015), pp. 101-118.

[13] J. W. Ross, "Creating a Strategic IT Architecture Competency: Learning in Stages", MIS Quarterly Executive, 2 (2003), pp. 31-43.

[14] J. W. Ross, P. Weill, and D. C. Robertson, Enterprise Architecture as Strategy, Harvard Business School Press, Cambridge, MA, 2006.

[15] V. Sambamurthy, A. Bharadwaj, and V. Grover, "Shaping Agility through Digital Options: Reconceptualizing 
the Role of Information Technology in Contemporary Firms", MIS Quarterly, 27 (2003), pp. 237-263.

[16] R. Sigala, A Process of Continuous Innovation: Centralizing Analytics at Caesars, in R. B. Ferguson, ed., MIT Sloan Management Review Interview. http://sloanreview.mit.edu/article/a-process-of-continuousinnovation-centralizing-analytics-at-caesars/ (accessed 3 September 2017), 2013.

[17] D. Sirmon, M. Hitt, J. Arregle, and J. Campbell, "The Dynamic Interplay of Capability Strengths and Weaknesses: Investigating the Bases of Temporary Competitive Advantage", Strategic Management Journal, 31 (2010), pp. 1386-1409.

[18] D. Sirmon, M. Hitt, and R. Ireland, "Managing Firm resources in Dynamic Environments to Create Value: Looking Inside the Black Box", The Academy of Management Review, 32 (2007), pp. 273-292.

[19] P. P. Tallon, "A Process-oriented Perspective on the Alignment of Information Technology and Business Strategy", Journal of Management Information Systems, 24 (2008), pp. 227-268.

[20] P. P. Tallon, "Value Chain Linkages and the Spillover Effects of Strategic IT Alignment: A Process-level View", Journal of Management Information Systems, 28 (2012), pp. $9-44$.

[21] P. P. Tallon, and A. Pinsonneault, "Competing Perspectives on the Link between Strategic Information Technology Alignment and Organizational Agility: Insights from a Mediation Model", MIS Quarterly, 35 (2011), pp. 463-486.

[22] H. Tanriverdi, "Information Technology Relatedness, Knowledge Management Capability, and Performance of Multibusiness Firms", MIS Quarterly, 29 (2005), pp. 311334.

[23] D. W. Wallace, J. L. Johnson, and U. Umesh, "Multichannels Strategy Implementation: The Role of Channel Alignment Capabilities", Decision Sciences, 40 (2009), pp. 869-900.

[24] P. Yetton, S. Henningsson, and N. Bjørn-Andersen, ""Ready to Acquire": The IT Resources Required for a Growth-by-Acquisition Business Strategy", MIS Quarterly Executive, 12 (2013), pp. 19-35.

\section{Appendix A. Survey Items \& Constructs}

SBU Agility (1: Strongly disagree; 5: Strongly agree)

Compared to the three nearest competitors, our SBU can easily and quickly...

a. Respond to changes in aggregate customer demand. b. Customize a product/service to suit an individual customer.

c. React to new product/service launch in the market.

d. Introduce new pricing schedules in response to changes in competitor's prices.

e. Expand into new regional and/or intl. markets.

f. Expand or reduce the variety of products / services available for sale.

g. Adopt new technologies to increase the throughput of products / services.

h. Switch suppliers or partners.

Utilization of Corporate IT Capabilities (1: Strongly disagree; 5: Strongly agree)

a. Corporate IT platform capabilities are falling short of the SBU's business requirements.

b. Overall, the corporate IT platform capabilities meet the needs of the SBU IT application portfolio.

c. Corporate IT platform capabilities are falling short of the SBU's IT requirements.

d. Together, corporate IT platform capabilities and SBU IT applications provide sufficient support for the SBU's IT requirements.

SBU Process Digitization (1: Not at all; 5: To a great extent)

To what extent is IT used to support key business activities in each of the following business processes?

a. Supplier relations.

b. Product/service operations.

c. Product/service enhancement.

d. Sales and marketing.

e. Customer relations.

SBU IT Autonomy (1: Corporate IT platform only; 3: Equally by SBU \& corporate IT platform; 5: SBU only)

Please indicate the sources of IT application support for the following business processes. Is IT support corporate IT platform only, SBU only or a combination of SBU and corporate IT platform?

a. Supplier relations.

b. Product/service operations.

c. Product/service enhancement.

d. Sales and marketing.

e. Customer relations.

SBU Market Uncertainty (1: Strongly disagree; 5: Strongly agree)

a. Environmental changes in our industry are very difficult to forecast.

b. Customer preferences in our business change a lot over time.

c. Regulation in our industry is continuously changing 